\title{
NIEVERGELT-PEARLMAN SYNDROME
}

\section{Synostosis in Feet and Hands with Dysplasia of Elbows \\ Report of a Case}

\section{H. J. Dubois, Pellenberg, Belgium}

From the Princess Elizabeth Orthopaedic Hospital, Exeter, England

In 1944, after a legal case of disputed paternity in Switzerland, Nievergelt reported three children with deformities like those of the alleged father. They had talipes with tarsal synostosis, dysplasia of the elbows with radio-ulnar synostosis and subluxation of the radial head, and dysplasia of the tibia and fibula with exostoses. So far as had been ascertained neither of the parents of the father, nor any other member of his family, presented similar malformations.

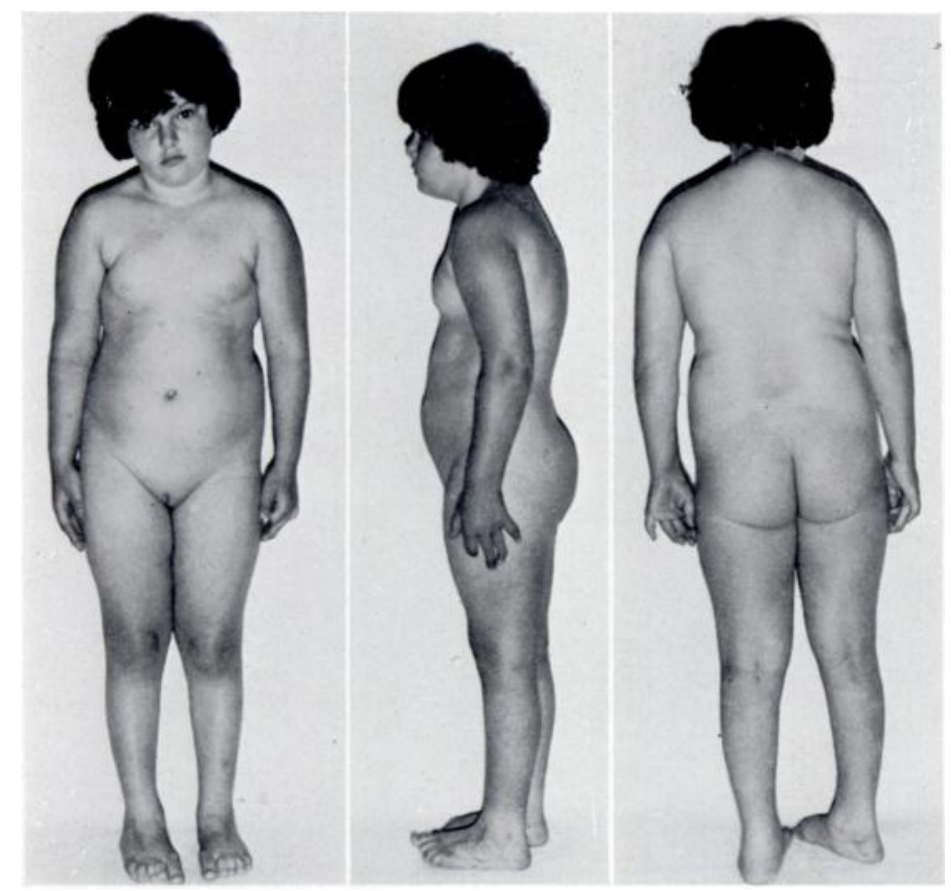

FIG. 1

The child aged 7 years.

In 1964 Pearlman, Edkin and Warren described a similar familial deformity in a woman and her daughter which he termed Nievergelt's syndrome. His patients, however, did not show dysplasia of the tibia and they also presented carpal synostosis, symphalangism, brachydactylia and clinocamptodactylia which were not mentioned in Nievergelt's original paper.

Congenital tarsal synostosis is uncommon, and only rarely has coalition of more than two tarsal bones been reported. Anderson, an Irish anatomist, reported a case of talo-navicular fusion in 1880. Similar coalitions were reported by Boyd (1944), Harris and Beath $(1948,1950)$, Herschel and von Ronnen (1950), Braddock (1961), Sanghi and Roby (1961), Schreiber (1963), Wray and Herndon (1963), Harris (1965), Simmons (1965) and Mitchell and Gibson (1967). Lamb (1958) described five cases of talo-calcaneo-navicular synostosis in which he observed an 
interesting abnormality of the ankle joint which had a "ball and socket" appearance and which allowed a few degrees of inversion and eversion of the heel to compensate for the fusion of the subtalar joint. Isolated cases of cubo-navicular and naviculo-cuneiform fusion have also been reported (Sel and Grand 1959, Lusby 1959). A single case of massive tarsal synostosis was found in the review of 830 radiographs of deformed feet by Shands and Wentz (1953), and a similar fusion was recorded by Bersani and Samilson (1957) as a familial malformation. Tarsal fusion in association with symphalangism was reported by Austin in 1951 and the same coincidence of fusions in two families was described by Geelhoed, Neel and Davidson (1969).

The case to be described resembles that of Pearlman and colleagues.

\section{CASE REPORT}

A girl, now aged seven and a half years, has attended the Princess Elizabeth Orthopaedic Hospital, Exeter, since she was seven months old. At that age she presented with symphalangism of the index, middle, ring and little fingers. When aged two years she walked with inverted feet: there was slight supination of the forefeet and complete lack of subtarsal movement. Radiographs showed massive tarsal synostosis. The supination of the forefeet gradually increased, mainly on the right side. When she was four years old calcaneal osteotomy was done on the right to correct the varus deformity of the heel, but this failed to influence the supination, which became severe on both sides.

The child was readmitted recently for further surgical treatment to correct the supination of the forefeet. At that time she was rather fat (Fig. 1): she was slightly retarded at school
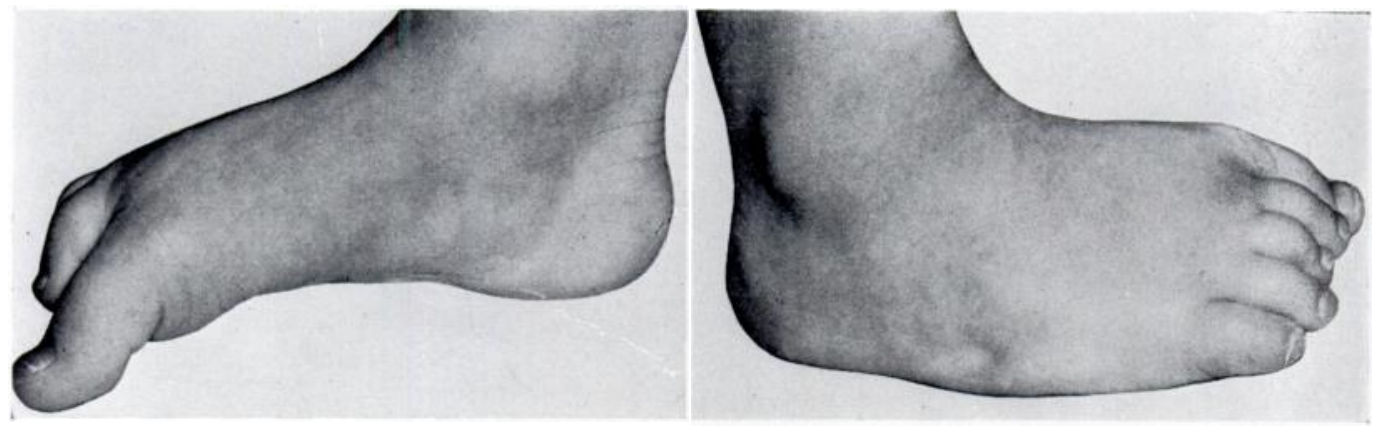

FIG. 2

The right foot showing the inability to take weight on the first metatarsal bone. The left foot was similar.
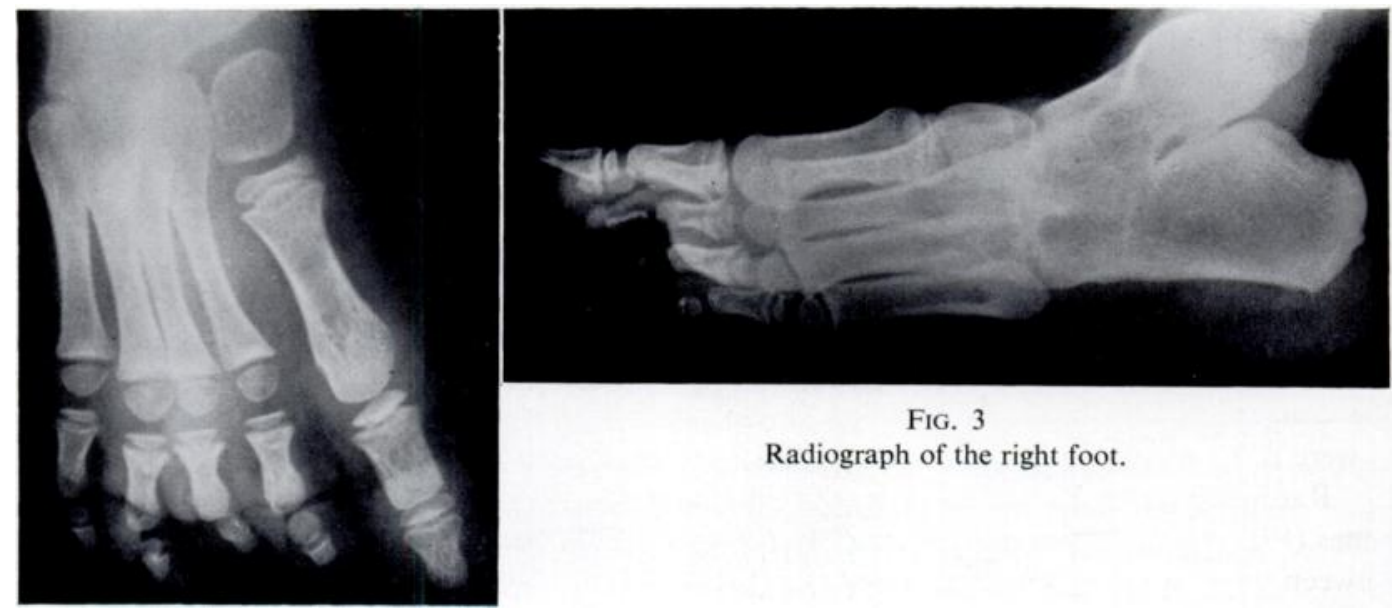

FIG. 3

Radiograph of the right foot. 
but seemed to have normal intelligence. She walked badly on the outer side of the feet, with the heels in slight valgus but the forefeet fixed in $\mathbf{4 5}$ degrees of supination. The first metatarsal bone did not bear weight (Fig. 2). The ankles allowed normal dorsiflexion and also about 20 degrees of inversion and eversion. In the hands the little fingers were short and there were only two phalanges in each finger (Fig. 4). She had difficulty in writing with her stiff fingers.

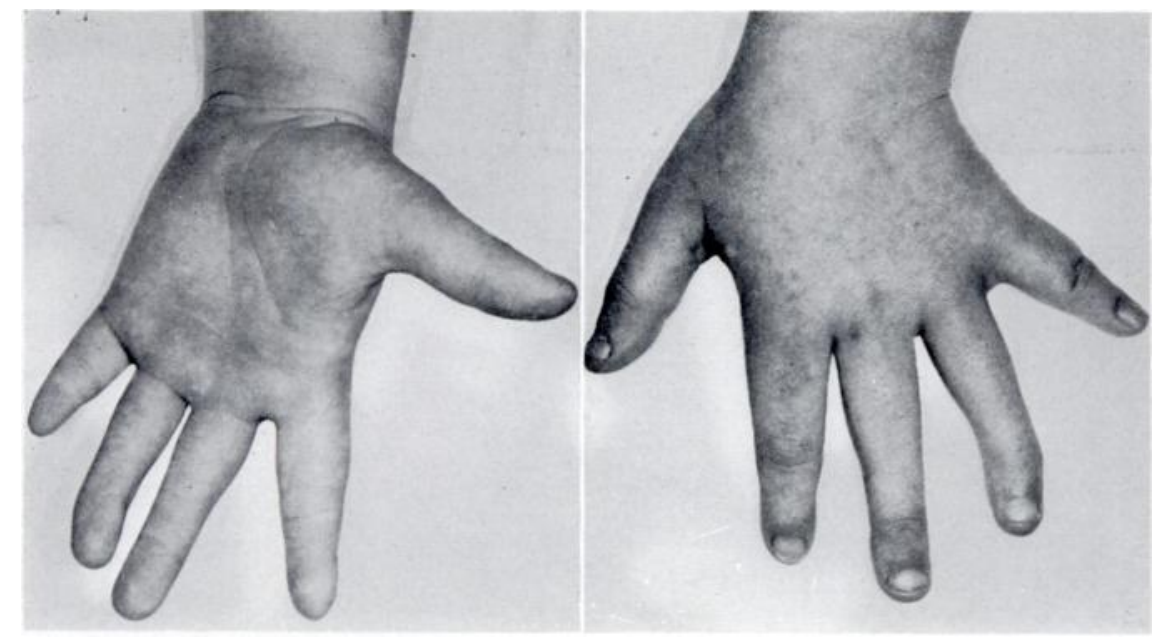

Fig. 4

The left hand to show the deformed fingers.

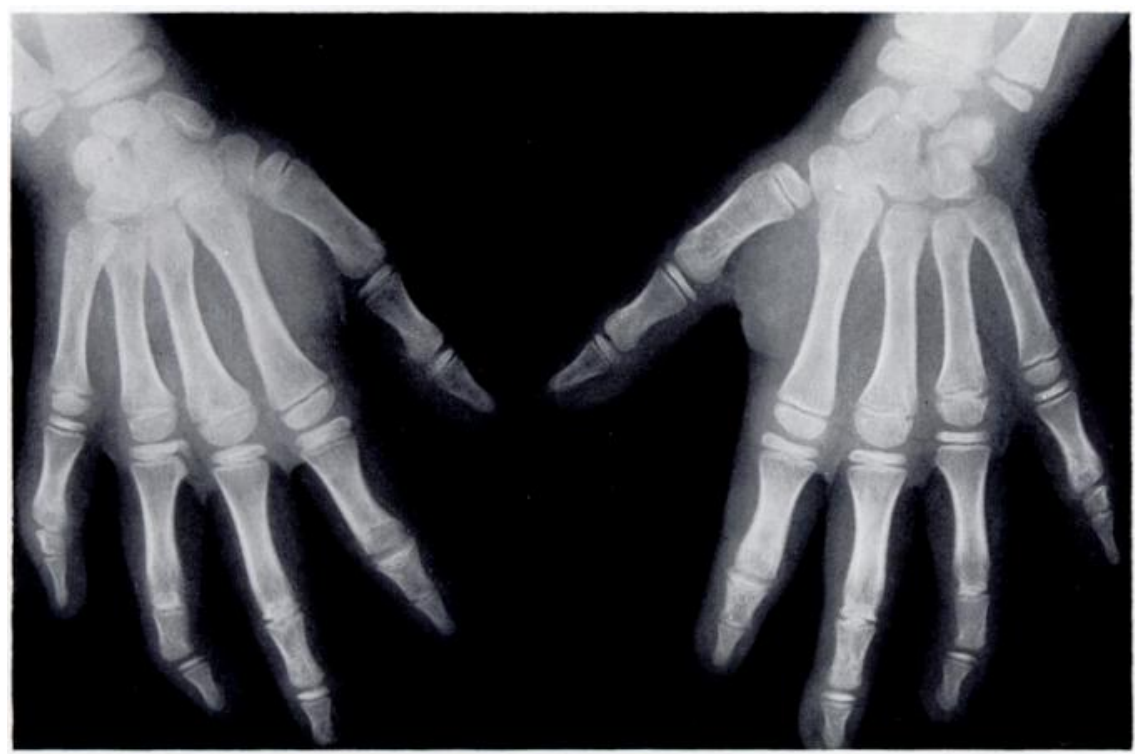

Fig. 5

Radiograph of the hands.

She complained of occasional pain in the elbows, but movements of these joints were full, as were those of the shoulders, hips and knees.

Radiographs of the feet showed synostosis of the talus, calcaneus, cuboid and cuneiform bones (Fig. 3). The second, third and fourth metatarsal bases were fused, with a bony bridge between them and the one tarsal bone. The medial cuneiform and first metatarsal bones were 


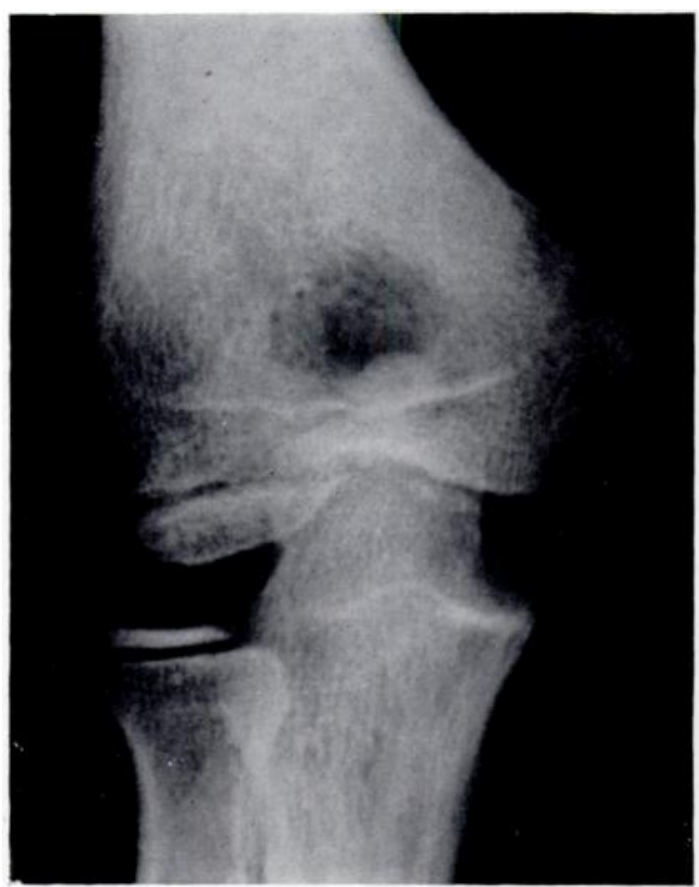

FIG. 6

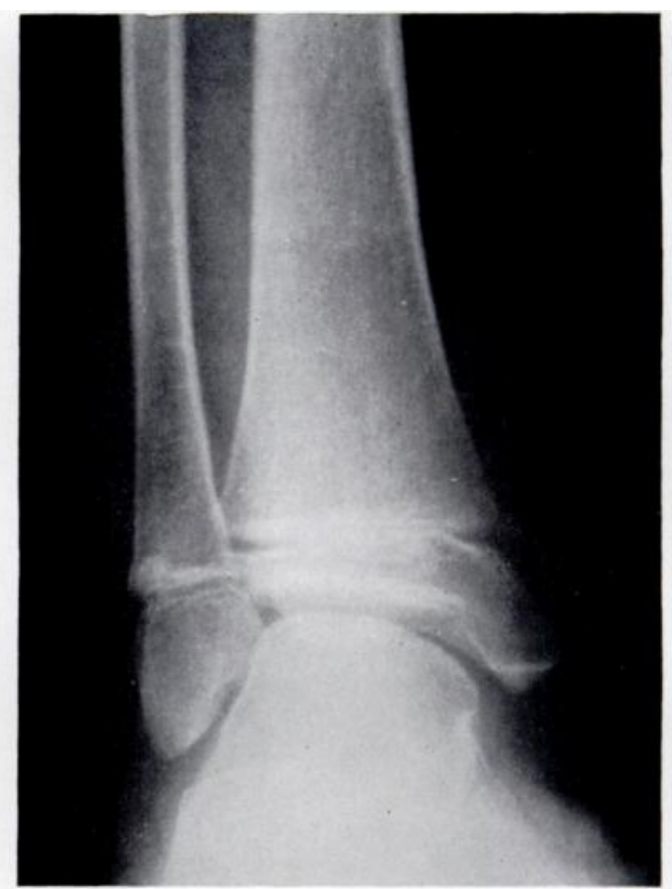

FIG. 7

Figure 6-Radiograph of the right elbow. Figure 7-Radiograph of the right ankle.

mobile. Radiographs of the hands (Fig. 5) showed fusion between the capitate and trapezoid bones and also between the triquetral bone and the hamate. There was also symphalangism at the proximal interphalangeal joints of the middle and ring fingers and at the distal interphalangeal joint of the index and little fingers.

A skeletal survey revealed dysplasia of the elbows (Fig. 6) and a typical "ball and socket" ankle (Fig. 7).

The parents and a younger brother have been examined and found normal; nor were any other members of the family affected.

\section{COMMENT}

As far as can be determined this is the only case in this family, but it conforms otherwise to the description of Nievergelt's syndrome as presented by Pearlman et al. in 1964, therefore it is suggested that "Nievergelt-Pearlman syndrome" would be more correct. The "ball and socket" ankle joint is probably caused by extensive tarsal synostosis to replace the missing subtalar movement (Lamb 1958). The coincidence of symphalangism and tarsal coalition could be caused by a single gene (Geelhoed et al. 1969), but this would be an occasional mutation because of the isolated occurrence of this case.

\section{SUMMARY}

1. A case of massive tarsal synostosis with supination of the forefeet, synostosis in the carpus with brachydactylia, clinicocamptodactylia, symphalangism and dysplasia of the elbows is presented.

2. This conforms to the description by Nievergelt (1944) and Pearlman et al. (1964).

I am indebted to Mr F. C. Durbin for his encouragement and help. I wish to thank Mr A. Barnett, photographer at the Princess Elizabeth Orthopaedic Hospital, for reproduction of the photographs and radiographs. 


\section{REFERENCES}

Anderson, R. J. (1880): The Presence of an Astragalo-scaphoid Bone in Man. Journal of Anatomy and Physiology, 14, 452.

Austin, F. H. (1951): Symphalangism and Related Fusions of Tarsal Bones. Radiology, 56, 882.

Bersani, F. A., and Samilson, R. L. (1957): Massive Familial Tarsal Synostosis. Journal of Bone and Joint Surgery, 39-A, 1187.

BOyD, H. B. (1944): Congenital Talonavicular Synostosis. Journal of Bone and Joint Surgery, 26, 682.

Braddock, G. T. F. (1961): A Prolonged Follow-up of Peroneal Spastic Flat Foot. Journal of Bone and Joint Surgery, 43-B, 734.

Geelhoed, G. W., Neel, J. V., and Davidson, R. T. (1969): Symphalangism and Tarsal Coalitions: A Hereditary Syndrome. Journal of Bone and Joint Surgery, 51-B, 278.

HARRIS, R. I. (1965): Retrospect-Peroneal Spastic Flat Foot (Rigid Valgus Foot). Journal of Bone and Joint Surgery, 47-A, 1657.

Harris, R. I., and BeAth, T. (1948): Etiology of Peroneal Spastic Flat Foot. Journal of Bone and Joint Surgery, 30-B, 624.

HaRris, R. I., and BeATH, T. (1950): John Hunter's Specimen of Talocalcaneal Bridge. Journal of Bone and Joint Surgery, 32-B, 203.

Herschel, H., and von Ronnen, J. R. (1950): The Occurrence of Calcaneonavicular Synosteosis in Pes Valgus Contractus. Journal of Bone and Joint Surgery, 32-A, 280.

LAMB, D. (1958): The Ball and Socket Ankle Joint-A Congenital Abnormality. Journal of Bone and Joint Surgery, 40-B, 240.

LUSBY, H. L. J. (1959): Naviculo-cuneiform Synostosis. Journal of Bone and Joint Surgery, 41-B, 150.

Mrtchell, G. P., and GiBson, J. M. C. (1967): Excision of Calcaneo-navicular Bar for Painful Spasmodic Flat Foot. Journal of Bone and Joint Surgery, 49-B, 281.

Nievergelt, K. (1944): Positiver Vaterschaftsnachweis auf Grund erblicher Missbildungen der Extremitäten. Archiv der Julius Klaus-Stiftung für Vererbungsforschung, Sozialanthropologie und Rassenhygiene, 19, 157.

Pearlman, H. S., Edkin, R. E., and Warren, R. F. (1964): Familial Tarsal and Carpal Synostosis with Radial-head Subluxation (Nievergelt's Syndrome). Journal of Bone and Joint Surgery, 46-A, 585.

SaNGHI, J. K., and RoBy, H. R. (1961): Bilateral Peroneal Spastic Flat Feet Associated with Congenital Fusion of the Navicular and Talus. Journal of Bone and Joint Surgery, 43-A, 1237.

SChreiber, R. R. (1963): Talonavicular Synostosis. Journal of Bone and Joint Surgery, 45-A, 170.

Sel, J. M. del and Grand, N. E. (1959): Cubo-navicular Synostosis. Journal of Bone and Joint Surgery, 42-B, 149.

Shands, A. R., and Wentz, I. J. (1953): Congenital Anomalies, Accessory Bones and Osteochondritis in the Feet of 850 Children. Surgical Clinics of North America, 33, 1643.

Simmons, E. H. (1965): Tibialis Spastic Varus Foot with Tarsal Coalition. Journal of Bone and Joint Surgery, 47-B, 533.

Wray, J. B., and HeRndon, C. N. (1963): Hereditary Transmission of Congenital Coalition of the Calcaneus to the Navicular. Journal of Bone and Joint Surgery, 45-A, 365. 